\title{
ABSENT MEIBOMIAN GLANDS: A MARKER FOR EEC SYNDROME
}

\author{
ELIZABETH BONNAR, PATRICIA LOGAN and PETER EUSTACE \\ Dublin, Ireland
}

\begin{abstract}
SUMMARY
A patient with a 20 year history of severe keratoconjunctivitis of unknown origin was found, on assessment at a blepharitis clinic, to have complete absence of meibomian glands. Further examination revealed the features of EEC syndrome. To our knowledge, this is the only case to have been diagnosed in this way. The ocular complications of EEC syndrome and other ectodermal dysplasias are reviewed.
\end{abstract}

The combination of ectrodactyly (lobster claw deformity of the hands and feet), ectodermal dysplasia (abnormalities of hair, teeth, nails and sweat glands) and cleft lip and palate, known as EEC syndrome, is a rare multiple congenital abnormality. ${ }^{1,2}$ Fewer than 180 cases have been reported in the literature. $^{3-5}$

Inheritance is autosomal dominant (AD), with incomplete penetrance and variable expressivity, so that not all features are present in every case. ${ }^{6}$ Sporadic cases also arise.

Ocular manifestations are frequent, the most common being disorders of the lacrimal drainage system $^{7,8}$ and sight-threatening keratopathy. ${ }^{9,10}$ Rarely, complete or partial absence of the meibomian glands has been recorded. ${ }^{9,11,12}$

In this paper we describe how a patient with a 20 year history of severe keratoconjunctivitis of unknown origin was found, on assessment at a blepharitis clinic, to have complete absence of meibomian glands. Further examination revealed the features of EEC syndrome. To our knowledge, this is the only case to have been diagnosed in this way.

\section{CASE REPORT}

A 23-year-old man presented with a spontaneous perforation of the left cornea, and a painful, red,

Correspondence to: Dr Elizabeth Bonnar, MRCOphth, University Department of Ophthalmology, Mater Misericordiae Hospital, Eccles Street, Dublin, Ireland. watering eye for the previous week. He gave a history of continuous attendance at eye clinics in various hospitals since the age of 3 years and was currently attending our own clinic, where he had last been seen 1 month previously. Maintenance medication was antiviral ointment and artificial tears. Old notes were unavailable on admission but there had been a previous spontaneous perforation of the left cornea at the age of 15 years, and an operation for a blocked tear duct on the right side at the age of 8 years.

Vision was $6 / 18$ on the right and hand movements on the left. There was marked photophobia and tearing on both sides. The left cornea was opacified and vascularised $360^{\circ}$, with central thinning and a small perforation just inferonasal to the pupil (Fig. 1 ). The right cornea was opacified and vascularised superiorly. Conservative management of the perforation was instituted. Because of 'severe blepharitis' thought to be contributory to the corneal condition, the patient was referred to a blepharitis clinic where he was seen the following morning. Screening procedures for blepharitis were carried out, and while the lids were thickened and red-rimmed, no evidence of recognisable blepharitis, or any associated skin condition such as atopy, eczema, rosacea or seborrhoea, could be found. ${ }^{13}$ Meibomian gland assessment, part of the screening procedure, ${ }^{14}$ revealed that there were no detectable duct orifices in any of the four eyelids (Fig. 2). No meibomian gland tissue could be demonstrated at the slit lamp, either by everting the lids or by transillumination. ${ }^{15}$ There was no evidence of hypoplastic glands, or of glands or ducts distorted by inflammation or destructive lid disease.

Complete absence of meibomian glands was suggestive of a congenital rather than an acquired cause. Congenital absence of meibomian glands is exceedingly rare, ${ }^{11,14}$ but has been reported in EEC syndrome $e^{9,11,12}$ and in anhidrotic ectodermal dysplasia. ${ }^{16,17}$ 


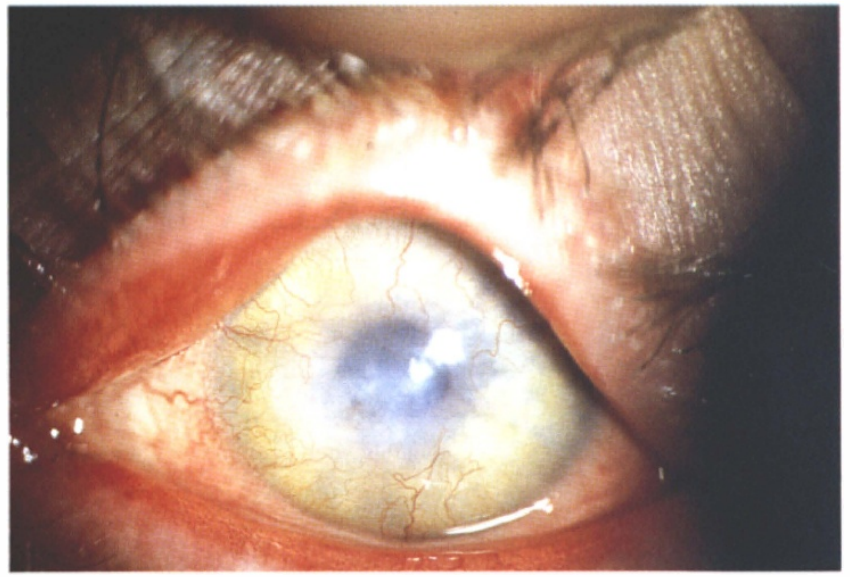

Fig. 1. Left cornea showing opacification, vascularisation and perforation.

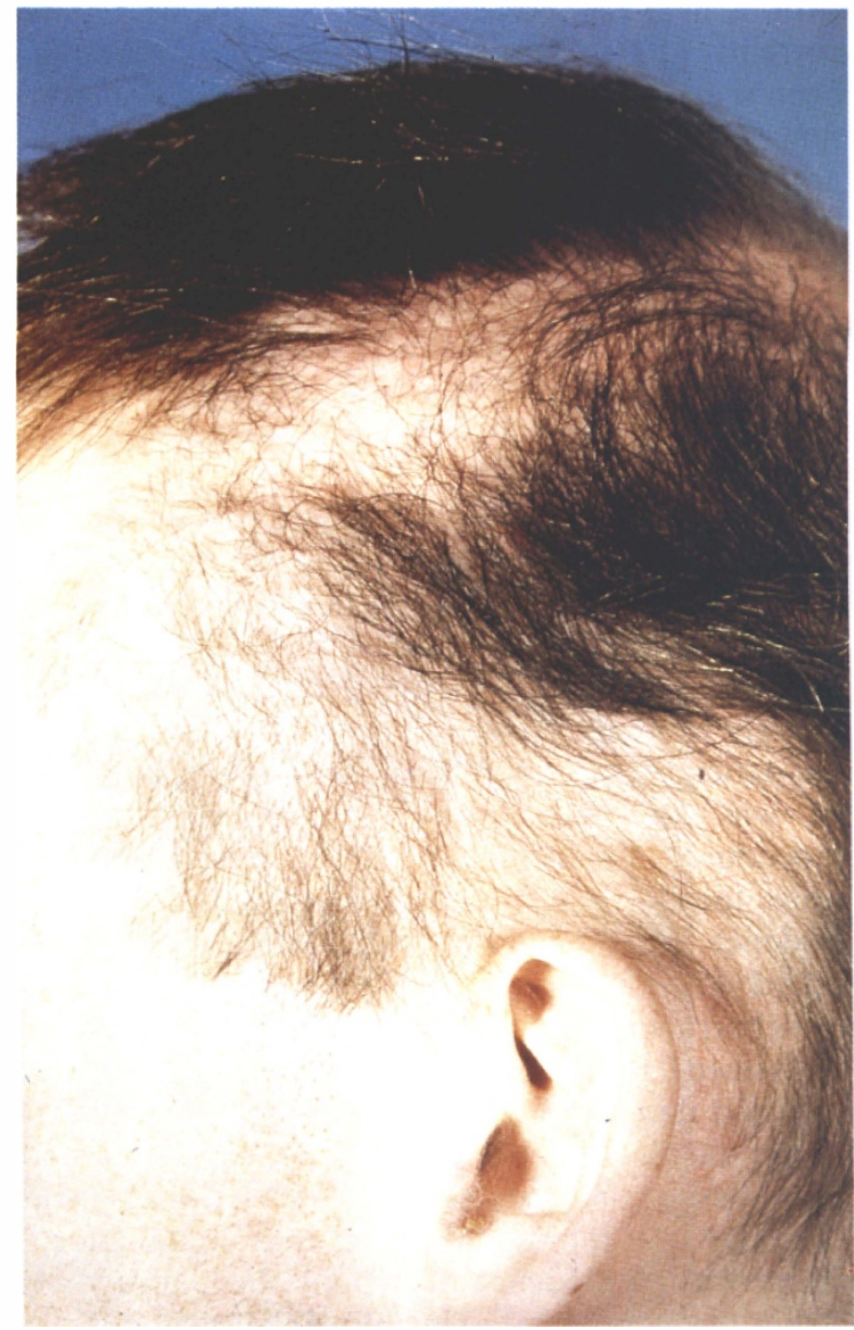

Fig. 3. Sparse scalp hair with wire-wool consistency.

The patient's hands showed no deformity and there was no cleft lip or palate. Although a history of sweating abnormality was absent, a search was made for the other features of ectodermal dysplasia. The hair, in addition to showing male pattern baldness,

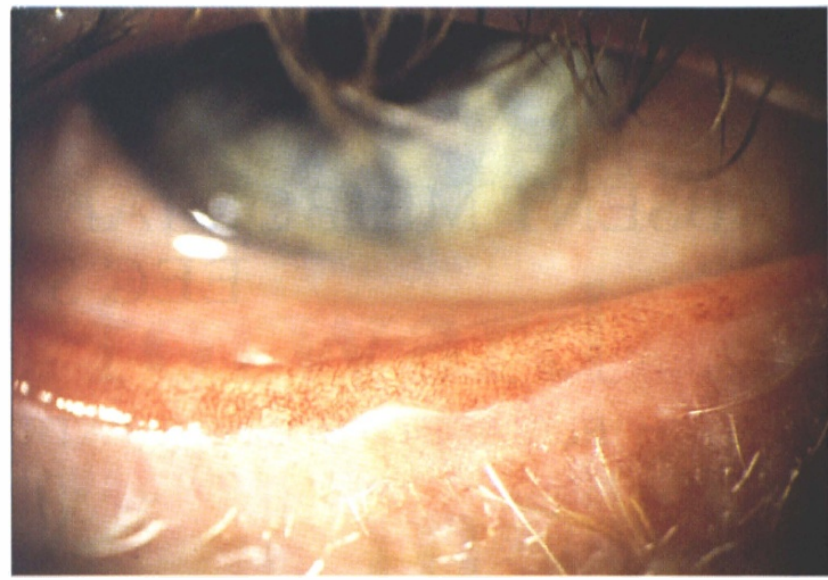

Fig. 2. Right lower lid showing absence of meibomian glands and duct openings.

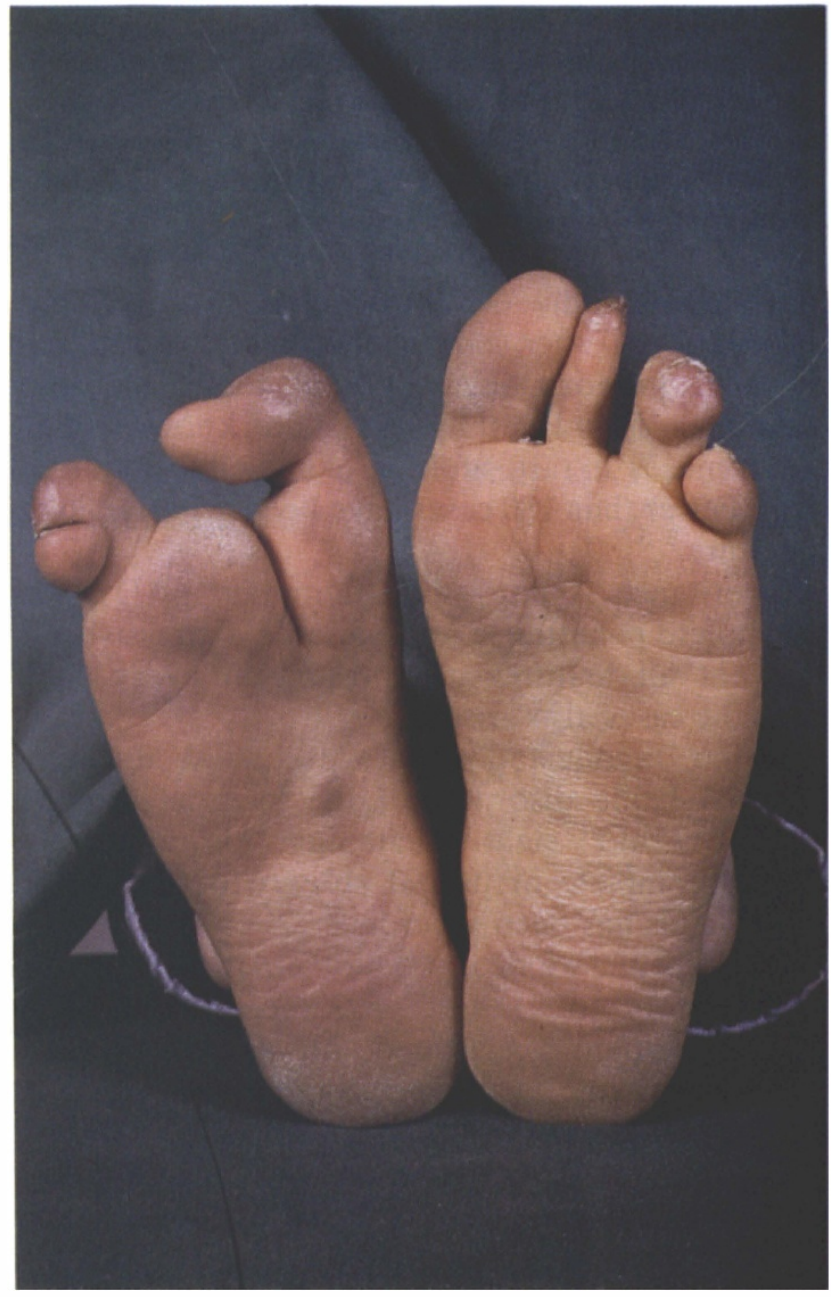

Fig. 4. Plantar view of the feet showing ectrodactyly of the right foot with syndactyly of toes three and four on the left.

was generally sparse and of a wire-wool consistency (Fig. 3). Eyebrows and eyelashes were also sparse. The teeth were grossly abnormal (Fig. 5). The fingernails were ridged, split and deformed (Fig. 6). Examination of the feet confirmed similar abnorm- 


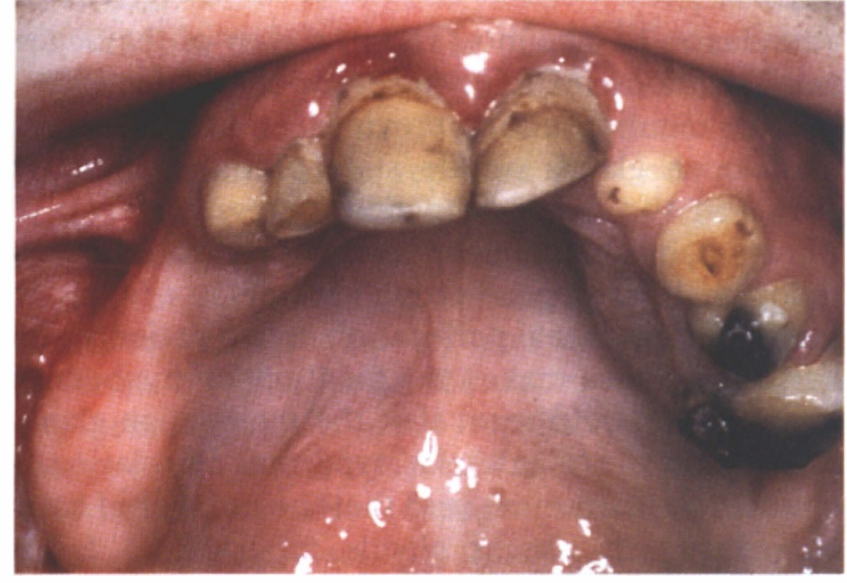

Fig. 5. Abnormal dentition: hypodontia and enamel dysplasia.

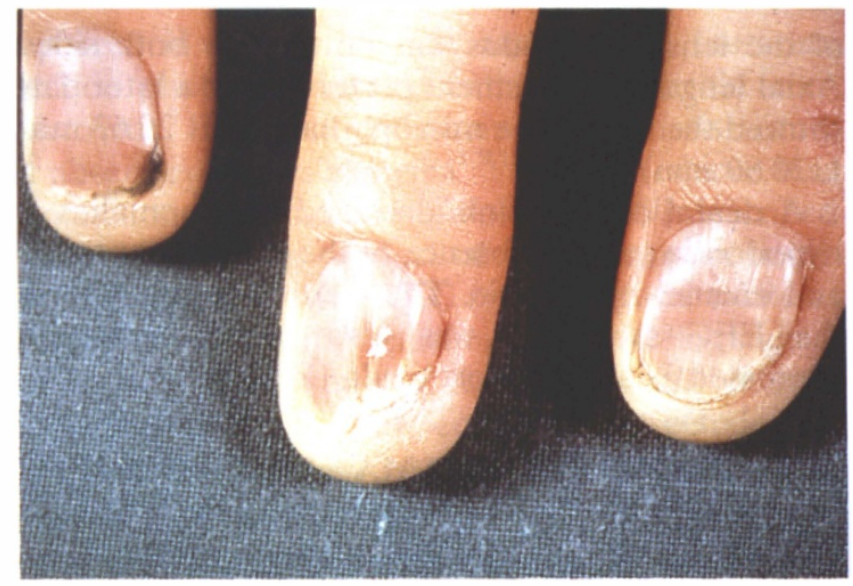

Fig. 6. Fingernails showing ridging and splitting.

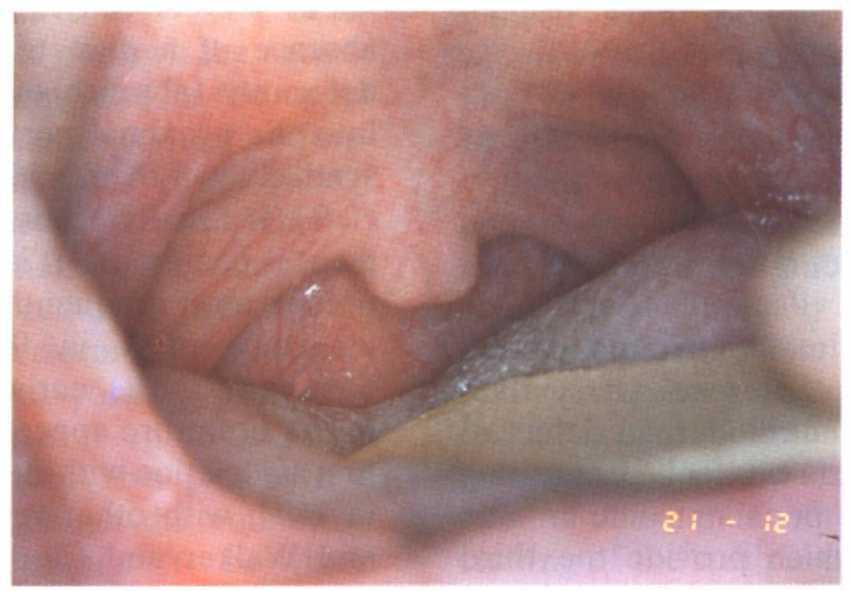

Fig. 7. View of soft palate showing bifid uvula.

alities in the toenails but also revealed ectrodactyly of the right foot, together with syndactyly of toes three and four of the left foot (Fig. 4). On the basis of these findings - ectrodactyly of the foot and abnormalities of the hair, teeth and nails - a diagnosis of EEC syndrome with incomplete expression was made.

The full history became available with the old notes. Since the age of 3 years the patient had attended ophthalmology clinics in various hospitals, initially with bilateral nasolacrimal obstruction and infection, present since birth. Repeated probings were carried out and at 8 years a successful right dacryocystorhinostomy (DCR) was performed. Examination at that time showed all four puncta to be closed by fibrosis. A lacrimal fistula was also present below the right lower punctum. Other features were extensive conjunctival fibrosis, and changes in the upper cornea on both sides, consisting of nebular opacification and ingrowth of pannus. Staff opinions were obtained in the different hospitals he attended. Trachoma, herpes simplex infection, Stevens Johnson syndrome and cicatricial pemphigoid were considered, but the aetiology of the keratoconjunctivitis remained obscure. The opacification and vascularisation of the left cornea gradually extended to $360^{\circ}$, central thinning developed and a spontaneous corneal perforation occurred when the patient was 15 years old. This healed with conservative management. Treatment thereafter consisted of antiviral ointment and artificial tears, with occasional topical antibiotics for intercurrent acute conjunctivitis. Persistent symptoms were photophobia, blepharospasm and mild epiphora.

Systematic re-examination following the diagnosis showed the palpebral fissures were narrow and the lid margins thickened. The mucocutaneous junction was sharply demarcated but very irregular (Fig. 2). Conjunctival fibrosis was present in both lower fornices with symblepharon on the left. Of the lacrimal puncta, only the right upper one could be located. Schirmer's test with anaesthesia gave $8 \mathrm{~mm}$ of wetting after 5 minutes on the right but only $3 \mathrm{~mm}$ on the left. With the addition of fluorescein there was complete absence of the lipid patterns normally seen, so that the tear film break-up time was not applicable. In a similar case ${ }^{11}$ the tear film breakup time was classified as instantaneous. Examination 
of the lens and fundus was normal on both sides. Axial length measurement performed at a later date showed the eyes to be microphthalmic (R $20.63 \mathrm{~mm}$, L $20.80 \mathrm{~mm}$ ).

A dental consultation identified the anomalies as hypodontia (partial absence of the permanent teeth) and enamel hypoplasia. The clefting component of the EEC syndrome was also found, minimally expressed as a bifid short uvula (Fig. 7).

\section{PROGRESS AND MANAGEMENT}

The perforation of the left cornea healed with conservative management. Conjunctival swabs grew Staphylococcus aureus sensitive to fucidin, which was prescribed for topical use. Occasional episodes of acute conjunctivitis on both sides have usually responded to Oc chloramphenicol. Nasal swabs at one point gave a heavy growth of $S$. aureus and the nasal carrier state was eliminated with the use of mupirocin nasal ointment. Maintenance therapy consists of artificial tears. The corneal signs remain stable, the corrected vision being 6/9 in the right eye and $2 / 60$ in the left.

In view of the absence of meibomian glands, the reduced tear production, the presence of symblepharon and probable inherent ectodermal defect of the cornea and conjunctiva, we feel penetrating keratoplasty would have a poor outcome in this patient. The goblet cells, which provide the third element of the tear film, may also be deficient due to inherent defects in the conjunctiva and secondary to conjunctival fibrosis. We do not feel either conjunctival biopsy or impression cytology is justified at present. Recurrent infection poses the greatest threat to the integrity of the cornea. The condition has stabilised since the eradication of the nasal carrier state for $S$. aureus and we consider this an important factor in the management.

\section{DISCUSSION}

There are estimated to be about 30-40 meibomian glands in the upper lid and $20-40$ in the lower. ${ }^{14}$ The glands or ducts may be affected by destructive or inflammatory lid disease. Congenital deficiency of the glands has been reported, ${ }^{18}$ but complete absence of the glands, the key to the diagnosis in our patient, is very rare. It has been reported in five previous cases of the EEC syndrome, ${ }^{11,12}$ with reduced or 'almost completely absent' glands being noted in three other cases. ${ }^{9,12}$ Absent meibomian glands have also been documented in two cases of anhidrotic/ hypohidrotic ectodermal dysplasia. ${ }^{16,17}$ Despite repeated examination over 20 years by a succession of ophthalmologists the absence of meibomian glands in this patient came to light only in the setting of a specialist blepharitis clinic. In two similar cases the defect was noted only after several years' attendance. ${ }^{9,11}$ The most recent review of the ocular manifestations of EEC syndrome published in $1989^{10}$ fails to mention either previous reports of absent meibomian glands or the state of the meibomian glands in the five new patients presented, two of whom had spontaneous corneal perforation. A report in 1990 of penetrating keratoplasty following spontaneous corneal perforation in two patients with EEC syndrome makes no mention of meibomian glands. ${ }^{19}$ It would seem that the meibomian glands suffer from the 'Cinderella' syndrome in relation to ophthalmic assessment, and that the number of cases of reduced or absent glands reported so far is artificially low.

Ectrodactyly or lobster claw deformity of the hands or feet can range from partial or complete absence of a digit to the full cleft hand or foot deformity (absence of the third digit with clefting into the proximal portion of the hand or foot and syndactyly of the remaining digits on each side of the cleft). It usually occurs bilaterally and foot involvement is common. ${ }^{20}$ It is inherited as an AD trait and occurs most frequently as an isolated defect. An incidence of 1 in 90000 has been quoted in Denmark. ${ }^{21}$ The earliest reference to ectrodactyly in the literature appears to have been in $1770 .^{21}$ Its first association with cleft lip and palate was recorded in 1804 , with other reports by Cockayne ${ }^{22}$ in 1936 and Walker and Clodius ${ }^{21}$ in 1963 , both of which stressed the common accompaniment of lacrimal tract abnormalities. The rare combination of ectrodactyly, ectodermal dysplasia and cleft lip and palate was not described until $1970 .{ }^{1}$ To date fewer than 180 cases have been reported in the literature. Associated findings in EEC syndrome include genitourinary anomalies, deafness, melanocytic naevi, scalp dermatitis, psychomotor retardation and microcephaly. ${ }^{4,5,7,11,23}$

The ectodermal dysplasias form a complex group of rare disorders involving one or more of the classic structures of ectodermal origin: hair, teeth, nails and sweat glands. ${ }^{2}$ They have been classified according to which structures are affected and over 121 syndromes have been described. ${ }^{3}$ The anhidrotic or hypohidrotic form is the best known, because of its distinctive trait of absent or reduced sweating, hypotrichosis and cone-shaped teeth. ${ }^{2}$ Besides EEC syndrome two other ectodermal dysplasias are commonly associated with clefting of the palate: Rapp-Hodgkin sydrome, with ectodermal dysplasia, cleft lip/palate and mid-facial hypoplasia, ${ }^{2,4}$ and Hay-Wells or AEC syndrome with ankyloblepharon, ectodermal defects and cleft lip/palate.,2,4,24

The ocular complications of EEC syndrome can be both disabling and sight-threatening. Anomalies of the lacrimal drainage system are common, being present in $84 \%$ of patients in one series. ${ }^{7}$ They range 
from absence or atresia of the puncta to incomplete development or absence of the canalicula, lacrimal sac or nasolacrimal ducts. ${ }^{8}$ Lacrimal drainage problems have also been reported with ectrodactyly alone, ${ }^{25,26}$ and with ectrodactyly and clefting. ${ }^{21,22}$ Similar abnormalities are found in patients with hypohidrotic ectodermal dysplasia, ${ }^{27}$ Rapp-Hodgkin syndrome, AEC syndrome, ${ }^{4}$ and other ectodermal dysplasias. ${ }^{4,7}$ Dacryocystorhinostomy when necessary generally gives good results. ${ }^{10}$ One patient besides our own had a lacrimal fistula. ${ }^{10}$

Keratopathy is also common, with typical early onset, and relentless progression from stromal infiltration and ingrowth of pannus to neovascularisation, opacification and thinning. ${ }^{8-12,19}$ Recurrent erosions $^{1}$ and ulceration ${ }^{8,11}$ have also been documented. In two patients besides our own the pannus and nebular opacification commenced in the upper third of the cornea. ${ }^{9,10}$ Spontaneous corneal perforation has occurred in four previous cases. ${ }^{10,19}$ Of these, two healed with conservative management ${ }^{10}$ and two responded well to penetrating keratoplasty, one requiring a repeat procedure. ${ }^{19}$ Penetrating keratoplasty has also been performed on an intact but opacified and vascularised cornea. ${ }^{9}$ Here the outcome was poor, with delay in re-epithelialisation and recurrence of opacification. This patient had absent meibomian glands, although the volume of aqueous tear production was thought to be within normal limits. A keratopathy similar to that found in EEC syndrome has also been noted in cases with ectrodactyly alone $\mathrm{e}^{26}$ and in anhidrotic ectodermal dysplasia. ${ }^{27,28}$ Aplasia or hypoplasia of the lacrimal glands leading to deficient tear production may be a feature of hypohidrotic ectodermal dysplasia.

Other ocular manifestations of EEC syndrome reported in the ophthalmic and general literature include photophobia, telecanthus, blepharitis, conjunctivitis, ${ }^{9}$ micro/anophthalmia ${ }^{29,30}$ trichiasis, scanty or absent eyebrows and cilia ${ }^{1,9,12,31}$ and reduced tear production. ${ }^{1,12}$ In addition, Wald ${ }^{32}$ in 1993 described a baby, the $2.5 \mathrm{~kg}$ product of a full-term uncomplicated pregnancy, with EEC syndrome and bilateral total tractional retinal detachment resembling stage 5 retinopathy of prematurity. Hayakawa et al..$^{33}$ in 1989 documented a case of ectrodactyly, ectodermal dysplasia and macular dystrophy - 'EEM syndrome' - and quoted reports of six similar cases, all autosomal recessive in inheritance and all born of consanguineous parents.

Table I summarises the ocular manifestations of EEC syndrome and other ectodermal dysplasias.

Full-blown EEC syndrome is easily recognised early in life and prenatal diagnosis by ultrasound is also possible. ${ }^{34}$ The variability of expression and lack of penetrance can make diagnosis difficult in the individual patient, ${ }^{6}$ and children with the full-blown syndrome may be born to a parent in whom the condition is minimally expressed. ${ }^{25}$ Since the syndrome was first described in 1970, the year this patient was born, it is not surprising that an early diagnosis was not made. Delay in diagnosis was compounded by the absence of lobster claw deformity of the hands, which is unusual, and minimal clefting of the soft palate.

Inheritance of the condition is $\mathrm{AD}$, with occasional sporadic mutations. Several reports emphasise the great phenotypic variability in EEC syndrome, the need for a careful search for microsymptoms in potential gene carriers, and the difficulties in genetic counselling. ${ }^{6,7.34}$ Family history in our patient, as yet incomplete, has so far been non-contributory.

Table I. The main features and ocular manifestations of EEC syndrome and other ectodermal dysplasias

\begin{tabular}{|c|c|c|c|c|c|}
\hline Syndrome & $\begin{array}{c}\text { EEC } \\
\text { syndrome }\end{array}$ & $\begin{array}{l}\text { Hypohidrotic } \\
\text { ectodermal } \\
\text { dysplasia }\end{array}$ & $\begin{array}{c}\text { AEC } \\
\text { syndrome }\end{array}$ & $\begin{array}{l}\text { Rapp-Hodgkin } \\
\text { syndrome }\end{array}$ & $\begin{array}{c}\text { EEM } \\
\text { syndrome }\end{array}$ \\
\hline Systemic manifestations & $\begin{array}{l}\text { Ectrodactyly, } \\
\text { ectodermal } \\
\text { dysplasia, cleft } \\
\text { lip/palate }\end{array}$ & $\begin{array}{l}\text { Hypohidrosis, } \\
\text { hypotrichosis, } \\
\text { cone-shaped } \\
\text { teeth }\end{array}$ & $\begin{array}{l}\text { Ankyloblepharon, } \\
\text { ectodermal } \\
\text { dysplasia, cleft } \\
\text { lip/palate }\end{array}$ & $\begin{array}{l}\text { Mid-facial } \\
\text { hypoplasia, } \\
\text { ectodermal } \\
\text { dysplasia, cleft } \\
\text { lip/palate }\end{array}$ & $\begin{array}{l}\text { Ectrodactyly, } \\
\text { ectodermal } \\
\text { dysplasia, } \\
\text { macular dystrophy }\end{array}$ \\
\hline Mode of inheritance & AD & $\begin{array}{l}\mathrm{AR} / \mathrm{X} \text {-linked } \\
\text { recessive }\end{array}$ & AD & $\mathrm{AD}$ & AR \\
\hline Sparse cilia/brows & + & + & + & - & + \\
\hline Blepharitis/conjunctivitis & + & - & + & + & - \\
\hline Photophobia/blepharospasm & + & + & + & - & - \\
\hline Lacrimal drainage anomalies & + & + & + & + & - \\
\hline Decreased lacrimation & + & + & - & - & - \\
\hline Reduced/absent meibomian glands & + & + & - & - & - \\
\hline Keratopathy & + & + & - & - & - \\
\hline Spontaneous corneal perforation & + & - & - & - & - \\
\hline Macular dystrophy & - & - & - & - & + \\
\hline Other & $\begin{array}{l}\text { Micro/ } \\
\text { anophthalmia, } \\
\text { retinal } \\
\text { detachment }\end{array}$ & $\begin{array}{l}\text { Glaucoma, } \\
\text { lenticular } \\
\text { opacities }\end{array}$ & $\begin{array}{l}\text { Microphthalmia, } \\
\text { cataract }\end{array}$ & - & \\
\hline
\end{tabular}

AD, autosomal dominant; AR, autosomal recessive. 
The pathological basis for the sight-threatening keratopathy in patients with EEC syndrome is probably multifactorial. By definition, tissues of both ectodermal and mesodermal origin may be affected. Baum and Bull $^{9}$ felt that the corneal abnormality was due to the primary ectodermal defects, since the keratopathy began in the upper part of the cornea, protected by the lid, while the exposed cornea was normal. Mondino et al. ${ }^{11}$ suggested that absent meibomian glands and reduced conjunctival goblet cells result in an unstable tear film, causing a breakdown in the ocular surface epithelium. In patients with reduced tear production and recurrent infections from obstruction to the nasolacrimal drainage system the cornea would be further compromised.

Reports of histopathological studies of ocular tissues from patients with EEC syndrome are few. Examination of the recipient corneal button from a 5-year-old child undergoing penetrating keratoplasty revealed the epithelium was markedly irregular in thickness, being thinned to a single cell layer in some areas. Bowman's membrane was also thinned in some areas and absent in others. The stroma showed typical changes of chronic inflammation and neovascularisation.9 A corneal specimen from a 30-year-old woman $^{11}$ showed an absent Bowman's zone and dense fibrous tissue in the anterior stroma, with focal accumulations of chronic inflammatory cells. Examination of palpebral and bulbar conjunctiva showed a squamous epithelium with rare goblet cells. The stroma contained strands of invaginated epithelium, dense hyalinised connective tissue, scattered mast cells and focal dense infiltrations of lymphocytes and plasma cells. Amyloid was present in the stroma of one upper lid. A wedge biopsy confirmed the clinical absence of meiboman glands in this patient and only a few glands of Zeis were seen.

A report of corneal changes in hypohidrotic ectodermal dysplasia ${ }^{28}$ gave a clinical picture of bilateral circumferential corneal pannus in association with markedly reduced tear production. The corneal specimen obtained at superficial keratectomy revealed epithelial acanthosis and dyskeratosis without keratinisation. Bowman's membrane was replaced with an inflammatory pannus of fibrovascular tissue, lymphocytes, plasma cells and a few eosinophils. Findings have thus been consistent with chronic inflammation but no changes specific to ectodermal dysplasia have emerged.

Patients with EEC syndrome and other ectodermal dysplasias may be referred to the ophthalmologist for assessment and management of their known ocular complications. Others, in whom these conditions may be only minimally expressed and hence remain undiagnosed, may present with serious ocular pathology of unknown aetiology. In such patients, systematic ophthalmological examination, including eyelid and meibomian gland assessment, is mandatory. Careful enquiry into the dermatological, developmental and family history may also prove fruitful.

Key words: EEC syndrome, Ectodermal dysplasia, Meibomian glands, Blepharitis, Keratitis, Penetrating keratoplasty.

\section{REFERENCES}

1. Rudiger RA, Haase W, Passarge E. Association of ectrodactyly, ectodermal dysplasia, and cleft lip-palate. Am J Dis Child 1970;120:160-3.

2. Harper J. Genetics and genodermatoses; ectodermal dysplasias. In: Champion RH, Burton JL, Ebling FJG, editors. Textbook of dermatology. Oxford: Blackwell Scientific, 1992:334-46.

3. Freire-Maia N, Pinheiro M. Ectodermal dysplasias: some recollections and a classification. Birth Defects 1988;24(2):3-14.

4. Fosko SW, Stenn KS, Bolognia JL. Ectodermal dysplasias associated with clefting: significance of scalp dermatitis. J Am Acad Dermatol 1992;27:249-56.

5. Nardi AC, Ferreira U, Netto Junior NR, et al. Urinary tract involvement in EEC syndrome: a clinical study in 25 Brazilian patients. Am J Med Genet 1992;44:803-6.

6. Penchaszadeh VB, De Negrotti TC. Ectrodactylyectodermal dysplasia-clefting (EEC) syndrome: dominant inheritance and variable expression. J Med Genet 1976;13:281-4.

7. Rodini ESO, Richieri-Costa A. EEC syndrome: report on 20 new patients, clinical and genetic considerations. Am J Med Genet 1990;37:42-53.

8. Kaiser-Kupfer M. Ectrodactyly, ectodermal dysplasia, and clefting syndrome. Am J Ophthalmol 1973;76: 992-8.

9. Baum JL, Bull MJ. Ocular manifestations of the ectrodactyly, ectodermal dysplasia, cleft lip-palate syndrome. Am J Ophthalmol 1974;78:211-6.

10. McNab AA, Potts MJ, Welham RAN. The EEC syndrome and its ocular manifestations. Br J Ophthalmol 1989;73:261-4.

11. Mondino BJ, Bath PE, Foos RY, et al. Absent meibomian glands in the ectrodactyly, ectodermal dysplasia, cleft lip-palate syndrome. Am J Ophthalmol 1984;97:496-500.

12. Pashayan HM, Pruzansky S, Solomon L. The EEC syndrome: report of six patients. Birth Defects 1974;10:105-27.

13. Bonnar E, Dowling S, Eustace P. A survey of blepharitis in pre-operative cataract patients. Eur J Implant Refract Surg 1994;6:87-92.

14. Bron AJ, Benjamin L, Snibson GR. Meibomian gland disease: classification and grading of lid changes. Eye 1991;5:395-411.

15. Robin JB, Jester JV, Nobe J, et al. In vivo transillumination biomicroscopy and photography of meibomian gland dysfunction. Ophthalmology 1985;92: 1423-6.

16. Holly FJ, Lemp MA. Tear physiology and dry eyes: review. Surv Ophthalmol 1977;22:69-87.

17. Ekins MBC, Waring GO. Absent meibomian glands and reduced corneal sensation in hypohidrotic ectodermal dysplasia. J Pediatr Ophthalmol Strabismus 1981;18:44-7.

18. Bron AJ, Mengher LS. Congenital deficiency of meibomian glands. Br J Ophthalmol 1987;71:312-4.

19. Mader TH, Doyle Stulting R. Penetrating keratoplasty 
in ectodermal dysplasia. Am J Ophthalmol 1990;110: 319-20.

20. Horton WA, Hood OJ. Ectrodactyly. In: Buyse ML, editor. Birth defects encyclopedia. Oxford: Blackwell Scientific, 1990:605-6.

21. Walker JC, Clodius L. The syndromes of cleft lip, cleft palate and lobster-claw deformities of hands and feet. Plast Reconstr Surg 1963;32:627-36.

22. Cockayne EA. Cleft palate, hare lip, dacryocystitis and cleft hand and feet. Biometrika 1936;28:60-3.

23. Jorgensen RJ. Ectrodactyly-ectodermal dysplasiaclefting syndrome. In: Buyse ML, editor. Birth defects encyclopedia. Oxford: Blackwell Scientific, 1990:607-8.

24. Spiegel J, Colton A. AEC syndrome: ankyloblepharon, ectodermal defects, and cleft lip and palate. J Am Acad Dermatol 1985;12:810-5.

25. Gualandri V, Ronzoni MG, Montagnani A, et al. Une famille atteinte de EEC syndrome (ectrodactily ectodermal-dysplasia clefting syndrome): variabilité clinique et conseil génétique. J Fr Ophtalmol 1986;9:855-7.

26. Wiegmann OA, Walker FA. The syndrome of lobster claw deformity and nasolacrimal obstruction. J Pediatr Ophthalmol 1970;7:79-85.

27. Beckerman BL. Lacrimal anomalies in anhidrotic ectodermal dysplasia. Am J Ophthalmol 1973;75: 728-30
28. Wilson FM, Grayson M, Pieroni D. Corneal changes in ectodermal dysplasia. Am J Ophthalmol 1973;75:17-27.

29. Viljoen DL, Smart R. Split-foot anomaly, microphthalmia, cleft-lip and cleft-palate, and mental retardation associated with a chromosome 6;13 translocation. Clin Dysmorphol 1993;2:274-7.

30. Rodini ES, Nardi A, Guion-Almeida ML, et al. Ectodermal dysplasia, ectrodactyly, clefting, anophthalmia/microphthalmia, and genitourinary anomalies: nosology of Goltz-Gorlin syndrome versus EEC syndrome. Am J Med Genet 1992;42:276-80.

31. Trueb RM, Bruckner-Tuderman L, Burg G. Ectrodactyly-ectodermal dysplasia-clefting syndrome with scalp dermatitis [letter]. J Am Acad Dermatol 1993;29:505.

32. Wald KJ, Hirose T, Topilow H. Ectodermal dysplasia, ectrodactyly, and clefting syndrome and bilateral retinal detachment. Arch Ophthalmol 1993;111:734.

33. Hayakawa M, Yanashima K, Kato K, et al. Association of ectodermal dysplasia, ectrodactyly and macular dystrophy: EEM syndrome [case report]. Ophthalmic Paediatr Genet 1989;10:287-92.

34. Anneren G, Andersson T, Lindgren PG, et al. Ectrodactyly-ectodermal dysplasia-clefting syndrome (EEC): the clinical variation and prenatal diagnosis. Clin Genet 1991;40:257-62. 